Gut, 1963, 4, 236

\title{
The electrophoretic pattern of normal human gastric juice and of the gastric juice of patients with gastric ulcer and gastric cancer ${ }^{1}$
}

\author{
D. W. PIPER, M. C. STIEL ${ }^{2}$, AND J. E. BUILDER \\ From the Department of Medicine, the University of Sydney, and the Unit of Clinical \\ Investigation, the Royal North Shore Hospital of Sydney, Sydney, Australia
}

EDITORIAL SYNOPSIS This study reports the electrophoretic pattern of the proteins in human gastric juice of control patients and patients with gastric ulcer and gastric carcinoma. Autodigestion was prevented by intragastric neutralization. The statistical limits of normal are defined and the changes found in the gastric juice of gastric ulcer and gastric patients with gastric carcinoma described.

Immunological studies have shown that all components of the plasma proteins are present in gastric juice (Heiskell, Wada, Stempien, Fukuda, Nakagawa, Yachi, Dagradi, and Carpenter, 1961) and in other secretions (Holman, Nickel, and Sleisenger, 1959) of the gastrointestinal tract. Electrophoretic components of the protein constituent of gastric juice have been studied in detail by Glass, Stephanson, and Rich (1957) and by Glass and Ishimori (1961) but these workers used acid gastric juice. Consequently, these studies revealed the protein pattern not as secreted into the stomach but after it has been digested in varying degree by the proteolytic enzymes in gastric juice. To determine more accurately the protein constituents of gastric juice the present investigation was undertaken where autodigestion was prevented by maintaining the $p \mathrm{H}$ of the gastric contents above 7 by intragastric neutralization.

The study reported below describes the electrophoretic pattern of the protein components of gastric juice in a series of control patients and in a group with simple gastric ulcer and a group with carcinoma of the stomach. We have attempted to define statistically the normal electrophoretic pattern of gastric juice, using the technique described, and to determine if patients with gastric ulcer and carcinoma showed significant quantitative or qualitative differences.

\footnotetext{
${ }^{1}$ Work supported by the Post Graduate Medical Foundation of the University of Sydney and the N.S.W. State Cancer Council.

${ }^{2}$ Clinical fellow in cancer, N.S.W. State Cancer Council.
}

METHODS

The controls studied were a series of 24 hospital inpatients in reasonably good health and free from gastrointestinal disease; all patients had normal serum proteins, and none had any evidence of heart failure. The group of 23 patients with gastric ulcers had the lesion demonstrated radiologically; patients with prepyloric ulcers were excluded from the series in view of the difficulty in differentiating a prepyloric ulcer from a duodenal ulcer. All of the group of 19 patients with carcinoma had the lesion demonstrated radiologically, 15 had the malignant lesion demonstrated at laparotomy, and biopsy was done in seven of these. Many of the gastric ulcer patients were studied on several occasions, 33 observations being made on these 23 patients.

The gastric juice was collected according to a method already described (Piper, Stiel, and Builder, 1962). The patients, after fasting overnight, were intubated and the gastric residue was aspirated. Thereafter, for the remainder of the test, 20 to $60 \mathrm{ml}$. of a varying dilution of a sodium bicarbonate solution (5\%) was injected intragastrically each five to 15 minutes and aspirated at similar intervals; the $p \mathrm{H}$ of the gastric contents was maintained at above 7 by frequent aspirations and determination of the $p H$ of the gastric contents using multirange indicator paper. Gastric secretion was stimulated with histamine using the technique of Kay (1953). Before the test was commenced 100 to $150 \mathrm{mg}$. bromsulphthalein was injected intravenously. If this appeared in the gastric juice, duodenal regurgitation was considered to have occurred; all specimens containing bile or bromsulphthalein were excluded from the study. It was found that bromsulphthalein was often obvious when bile staining of the gastric contents was not present. After aspiration, the gastric juice was filtered through gauze to remove 

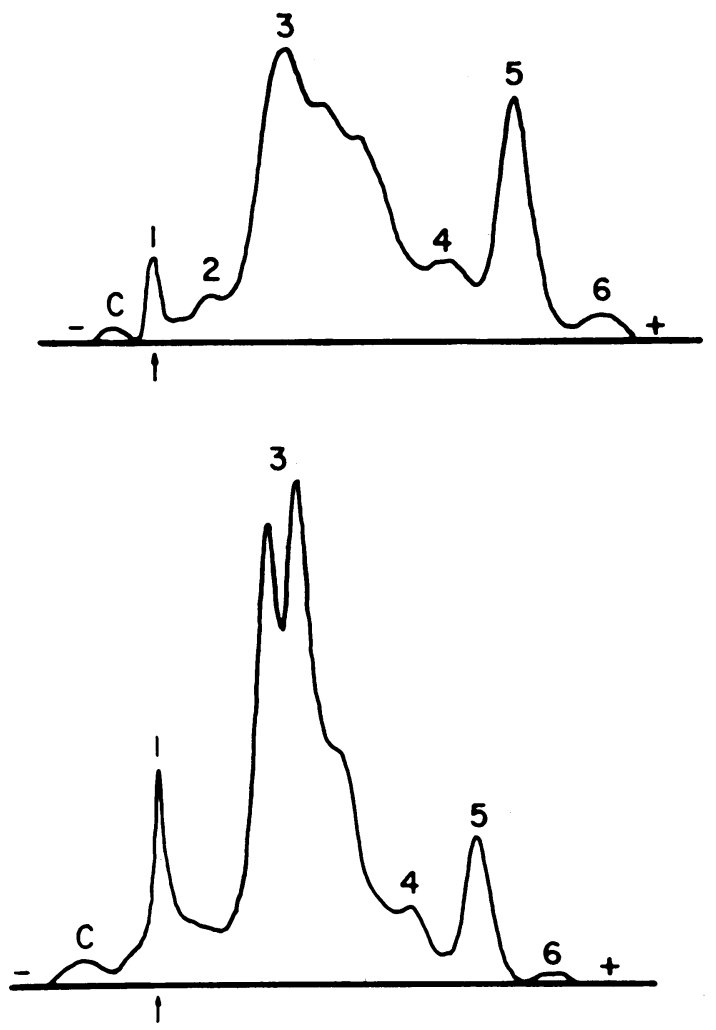

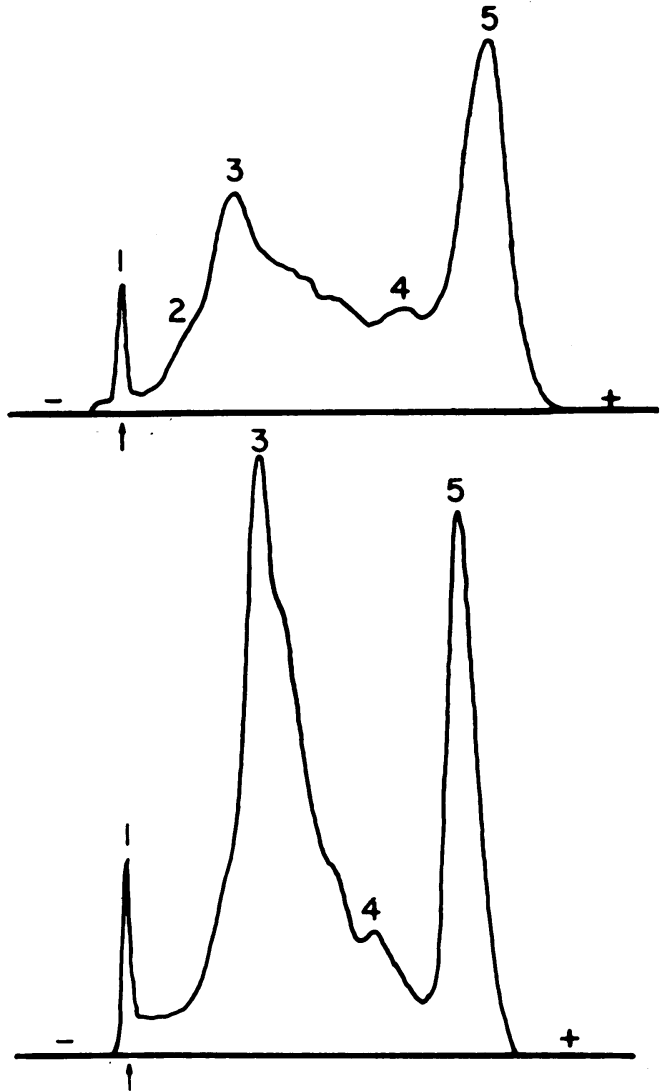

FIG. 1. Electrophoretic patterns in normal human gastric juice in four patients.

visible mucus, dialysed at $5^{\circ} \mathrm{C}$. against five changes of distilled water for 24 hours, filtered through Whatman's no. 1 filter paper, and lyophilized. Approximately $1 \mathrm{mg}$. was then electrophoresed using the technique of Glass et al. (1957) except that in this case horizontal electrophoresis apparatus and cellulose acetate strips (Kohn, 1957) were used. The strips were stained with Amidoblack (Glass et al., 1957), and scanned using a Spinco Analytrol. The area under each band was determined by dropping vertical lines from the minima adjoining each band and this was used as a measure of protein present in each band.

\section{RESULTS}

THE NORMAL ELECTROPHORETIC PATTERN Twentyfour observations were made on as many patients. The normal pattern consisted of three major bands that moved towards the anode and a band that remained at the application site (Fig. 1). In 13 cases $(55 \%)$ a small band appeared that moved towards the cathode. In a proportion of cases, two further anodal bands appeared, one migrating at a slow rate and another that migrated more rapidly than the main band that moved towards the anode. The anodal peaks were named from left to right 1 to 6 , band 1 corresponding to the band that remained at the application site (Fig. 1). The major bands present in normal patients were bands $1,3,4$, and 5 ; band 3 may be divided into as many as three minor bands. If a band migrated towards the cathode, it was termed band $\mathrm{C}$. Band 5 migrated at all $p \mathrm{H}$ levels at the same rate as human albumin. The following bands were present in only a small number of normal patients; band 2, present in two cases $(8 \%)$; band 6 present in seven cases $(29 \%)$.

The distances migrated by the bands were expressed relative to the distance migrated by band 5 , because the latter had been shown to migrate at the same rate as human albumin. The frequency distribution of the distances migrated by each band and the size of each band is shown in Fig. 2; it is seen that the distances fall naturally into fairly well 


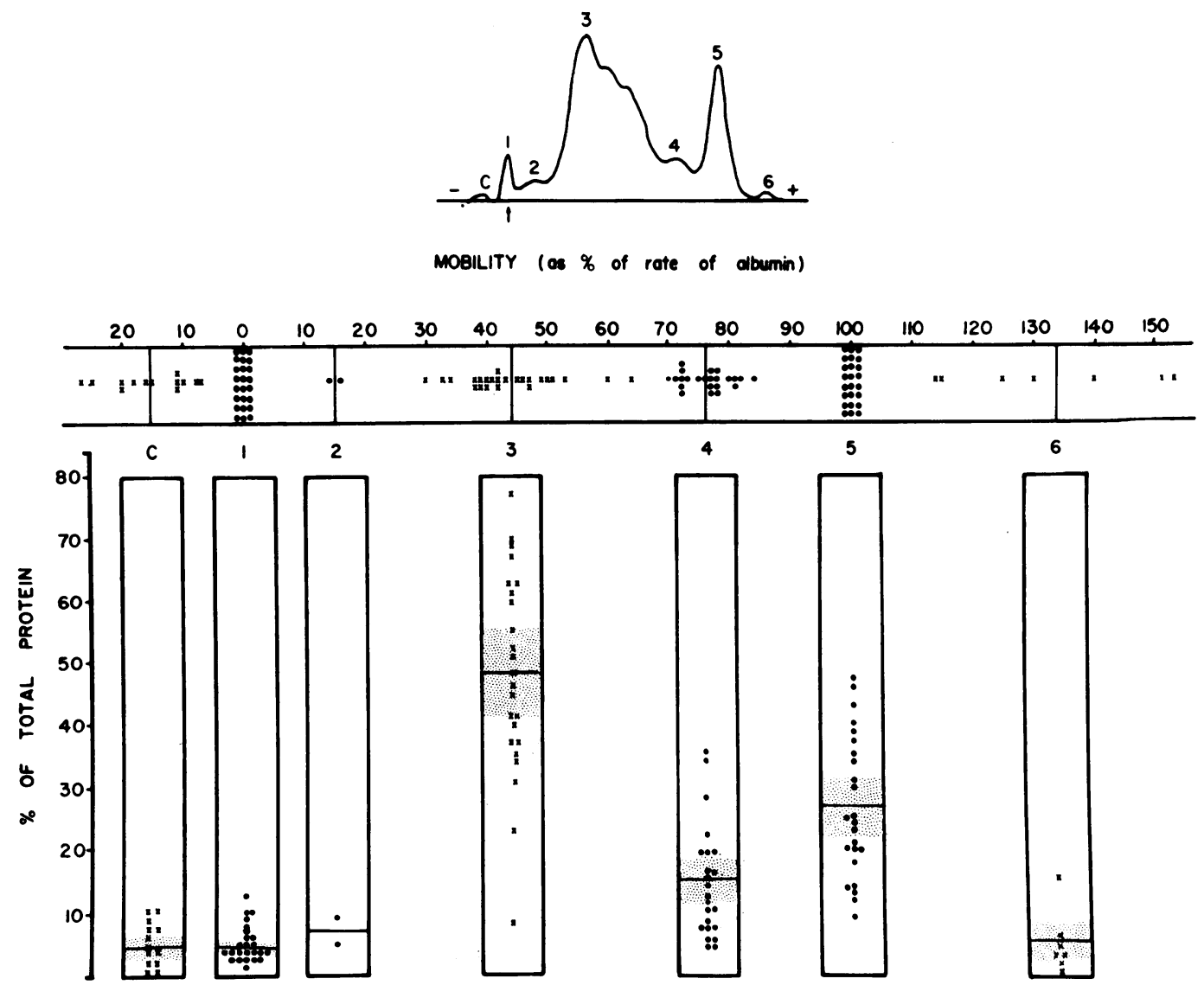

FIG. 2. Electrophoretic pattern in normal human gastric juice. Findings in 24 patients expressed in terms of distance migrated by each band and the percentage of the total protein-staining material occurring in each band.

defined groups for each band. Expressing the distances migrated in terms of distance migrated by band 5 (albumin), a band was considered band 1 if it remained at the application site, band 2 if it migrated up to $29 \%$ of this distance, band 3 if it migrated $30 \%$ to $68 \%$ of this distance, and band 4 if it migrated $68 \%$ to $84 \%$ of the distance migrated by band 5 . Any band anterior to band 5 was termed band 6 , and any band that migrated towards the cathode band $\mathrm{C}$.

The quantitative aspects of these bands in controls and patients with gastric ulcer and gastric carcinoma is given in Fig. 3 to Fig. 5 and Table I, and the significance of the difference between the three groups in Table II. One possible source of error in these quantitative estimates is the extent of albumin trailing; we have found, however, using cellulose acetate strips and applying pure albumin, that the albumin trail is very small and far less than that seen when albumin is electrophoresed on Whatman's electrophoresis paper.
A survey of the results in Figs. 3, 4, and 5 and Tables I and II shows:-

1 In gastric ulceration, the most obvious abnormality is the high incidence of band 2 . This band was present in two of the 24 control observations, two of the 19 observations on patients with gastric carcinoma, and 16 of the 33 observations in the gastric ulcer patients studied. This increased frequency of band 2 in the gastric ulcer group is highly significant $(P=0.001)$. Also band 6 was less frequent in the gastric ulcer group $(P=0.05)$. When the size of the bands is compared it is found that band 5 is increased in the gastric ulcer group $(P=0.05)$ whereas bands 4 and 6 are reduced $(P=0.05)$; when band 2 was present in the control group it was small.

2 The most obvious abnormality in patients with carcinoma of the stomach is the accentuation of band 5 (albumin) (Fig. 5 and Tables I and II). Band 4 was greater in the gastric carcinoma group when compared with the gastric ulcer group, but in 


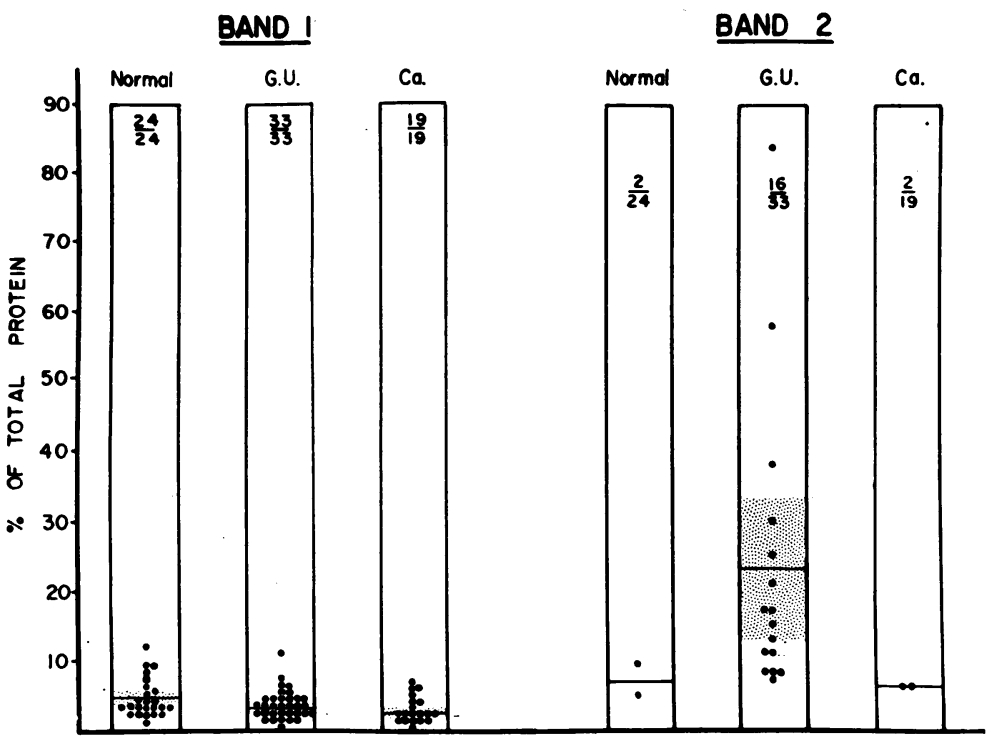

FIG. 3. The percentage of the total protein-staining material occurring in bands 1 and 2 in a group of patients with gastric ulcer and gastric carcinoma compared with the normal findings.

BAND 3

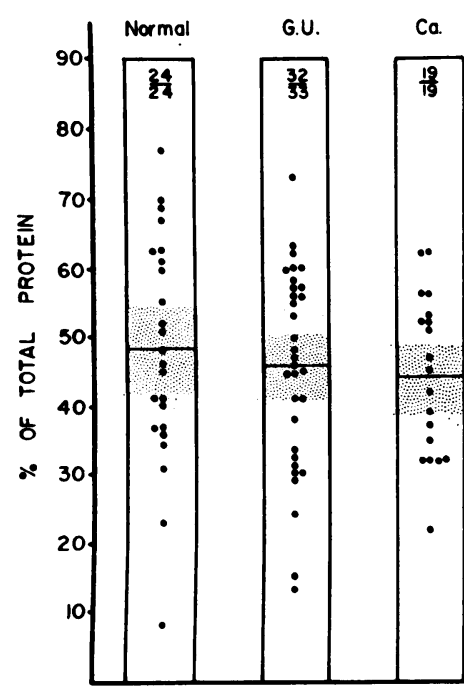

BAND 4

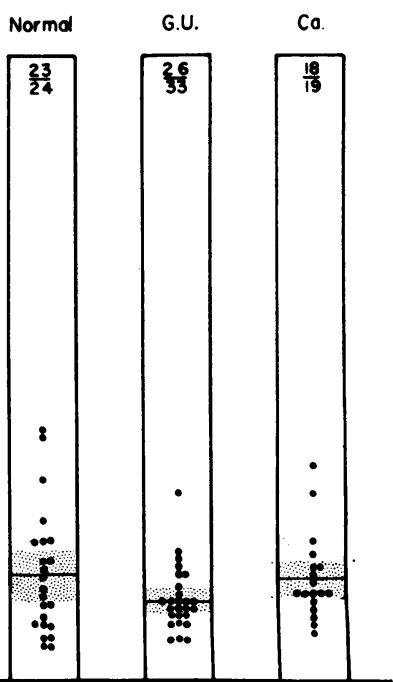

the gastric carcinoma group it did not differ significantly from the control group. Also in this group, bands $C$ and 6 were significantly reduced when compared with the control group.

3 Comparing the ulcer and carcinoma groups, the frequency of band 2 is increased in the gastric ulcer group and quantitatively bands 2 and 6 are reduced in the gastric carcinoma group and band 4 is reduced in the gastric ulcer series.

In this study an accurately weighed portion of lyophilized gastric juice was not applied. Though we do not feel variation in the amount applied would influence the above results, as albumin trailing is negligible when cellulose acetate strips are used and the scanning apparatus used was very sensitive, we did compare the amount of protein staining material on the whole electrophoresis strip in the three groups studied. The saw teeth on the integration trace were counted and used as an index of the amount of protein staining material on each strip. In the controls the number of saw teeth was $231 \pm 21$, in gastric ulcer $227 \pm 13$, and in gastric carcinoma $177 \pm 18$. The amount of protein staining material applied was statistically less in the carcinoma
FIG. 4. The percentage of the total protein-staining material occurring in bands 3 and 4 in a group of with gastric ulcer and gastric carcinoma compared with the normal findings. 
BAND 5

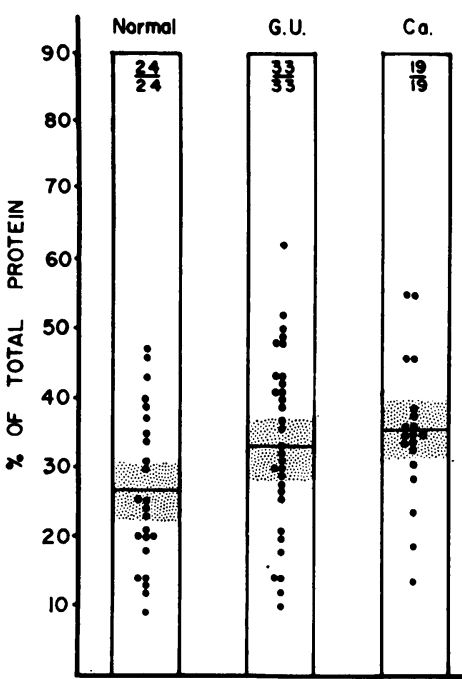

BAND 6

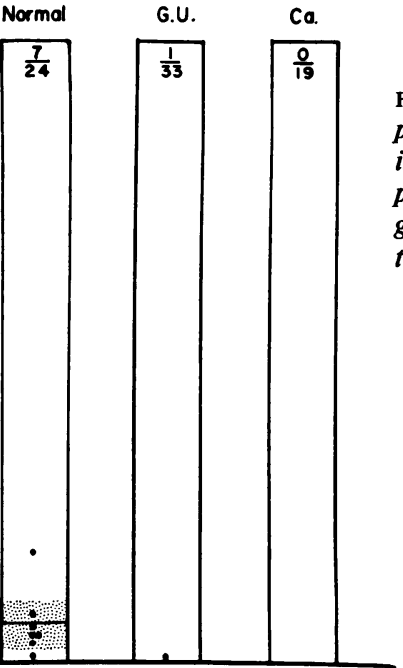

TABLE I

RESULTS IN CONTROL PATIENTS AND PATIENTS WITH GASTRIC ULCER AND CARCINOMA OF STOMACH

\begin{tabular}{|c|c|c|c|c|c|c|c|}
\hline Band & $C$ & 1 & 2 & 3 & 4 & 5 & 6 \\
\hline $\begin{array}{l}\text { Controls (24) } \\
\text { No. showing band } \\
\text { Size of band }{ }^{1} \text { Mean } \\
\\
\text { S.E. }\end{array}$ & $\begin{array}{l}13 \\
4 \cdot 7 \\
0 \cdot 9\end{array}$ & $\begin{array}{l}24 \\
4 \cdot 4 \\
0 \cdot 5\end{array}$ & $\begin{array}{l}2 \\
7 \cdot 0 \\
1 \cdot 4\end{array}$ & $\begin{array}{l}24 \\
48 \cdot 1 \\
3 \cdot 3\end{array}$ & $\begin{array}{l}23 \\
15 \cdot 2 \\
1 \cdot 8\end{array}$ & $\begin{array}{l}24 \\
26 \cdot 7 \\
2 \cdot 2\end{array}$ & $\begin{array}{l}7 \\
5 \cdot 7 \\
1 \cdot 7\end{array}$ \\
\hline $\begin{array}{l}\text { Gastric ulcer } 33(23) \\
\text { No. showing band } \\
\text { Size of band Mean } \\
\\
\text { S.E. }\end{array}$ & $\begin{array}{c}10(7) \\
3 \cdot 0 \\
1 \cdot 1\end{array}$ & $\begin{array}{l}33(23) \\
3 \cdot 2 \\
0 \cdot 4\end{array}$ & $\begin{array}{l}16(13) \\
23 \cdot 2 \\
5 \cdot 1\end{array}$ & $\begin{array}{l}32(22) \\
45 \cdot 4 \\
2 \cdot 5\end{array}$ & $\begin{array}{l}26(17) \\
11.4 \\
0.9\end{array}$ & $\begin{array}{l}33(23) \\
33 \\
2 \cdot 3\end{array}$ & $\begin{array}{l}2(2) \\
1 \cdot 5 \\
0 \cdot 4\end{array}$ \\
\hline 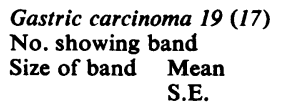 & $\begin{array}{l}4(3) \\
1 \cdot 3 \\
0 \cdot 5\end{array}$ & $\begin{array}{c}19(17) \\
2 \cdot 8 \\
0 \cdot 4\end{array}$ & $\begin{array}{l}2(2) \\
6 \cdot 0 \\
0\end{array}$ & $\begin{array}{l}19(17) \\
44 \cdot 2 \\
2 \cdot 5\end{array}$ & $\begin{array}{l}18(16) \\
14 \cdot 6 \\
1.4\end{array}$ & $\begin{array}{l}19(17) \\
35 \cdot 5 \\
2 \cdot 3\end{array}$ & $\begin{array}{l}0(0) \\
0 \\
0\end{array}$ \\
\hline
\end{tabular}

${ }^{1}$ The size of each band represents the percentage of the total protein-staining material on the electrophoresis strip in each band. The number after each group and under each band represents the number of observations made, and the bracketed number shows the number of patients showing each band in their first study. No control patient was investigated on more than one occasion.

\section{TABLE II}

COMPARISON OF RESULTS IN CONTROL PATIENTS AND PATIENTS WITH GASTRIC ULCER AND CARCINOMA OF THE STOMACH

\begin{tabular}{|c|c|c|c|c|c|c|c|}
\hline Band & $C$ & 1 & 2 & 3 & 4 & 5 & 6 \\
\hline $\begin{array}{l}\text { Controls and gastric ulcer } \\
\text { Frequency of bands ( } \chi^{2} \text { test) } \\
\text { Size of bands-difference } \\
P \text { ( } t \text { test) }\end{array}$ & $\begin{array}{l}\text { N.S. } \\
1 \cdot 7 \\
\text { N.S. }\end{array}$ & $\begin{array}{l}\text { N.S. } \\
1 \cdot 2 \\
\text { N.S. }\end{array}$ & $\begin{array}{c}0.001 \\
16.2 \\
P<0.01\end{array}$ & $\begin{array}{l}\text { N.S. } \\
2 \cdot 7 \\
\text { N.S. }\end{array}$ & $\begin{array}{l}\text { N.S. } \\
3 \cdot 8 \\
0 \cdot 05\end{array}$ & $\begin{array}{l}\text { N.S. } \\
6 \cdot 3 \\
0 \cdot 05\end{array}$ & $\begin{aligned} 0.05 \\
4.2 \\
P<0.05\end{aligned}$ \\
\hline $\begin{array}{l}\text { Controls and gastric cancer } \\
\text { Frequency ( } \chi^{2} \text { test) P } \\
\text { Size of bands-difference } \\
\text { Significance } P \text { ( } t \text { test) }\end{array}$ & $\begin{aligned} & 0.05 \\
& 3.4 \\
< & 0.01\end{aligned}$ & $\begin{array}{l}\text { N.S. } \\
1.6 \\
<0.02\end{array}$ & $\begin{array}{l}\text { N.S. } \\
1.0 \\
\text { N.S. }\end{array}$ & $\begin{array}{l}\text { N.S. } \\
3 \cdot 9 \\
\text { N.S. }\end{array}$ & $\begin{array}{l}\text { N.S. } \\
0.6 \\
\text { N.S. }\end{array}$ & $\begin{array}{l}\text { N.S. } \\
8 \cdot 8 \\
0 \cdot 01\end{array}$ & $\begin{aligned} \mathbf{P} & <0.05 \\
& 5.7 \\
& <0.01\end{aligned}$ \\
\hline $\begin{array}{l}\text { Gastric ulcer and gastric cancer } \\
\text { Frequency ( } \chi^{2} \text { test) } \mathrm{P} \\
\text { Size of bands-difference } \\
\text { Significance } \mathrm{P} \text { ( } \mathrm{t} \text { test) }\end{array}$ & $\begin{array}{l}\text { N.S. } \\
1 \cdot 7 \\
\text { N.S. }\end{array}$ & $\begin{array}{l}\text { N.S. } \\
0.4 \\
\text { N.S. }\end{array}$ & $\begin{array}{c}0.01 \\
17.2 \\
P<0.01\end{array}$ & $\begin{array}{l}\text { N.S. } \\
1 \cdot 2 \\
\text { N.S. }\end{array}$ & $\begin{array}{l}\text { N.S. } \\
3 \cdot 2 \\
0.05\end{array}$ & $\begin{array}{l}\text { N.S. } \\
\mathbf{3 \cdot 2} \\
\text { N.S. }\end{array}$ & $\begin{aligned} & \text { N.S. } \\
& 1.5 \\
&< 0.00\end{aligned}$ \\
\hline
\end{tabular}

As the groups were small, Yates' correction was applied when $\chi^{2}$ test was used.

N.S. = not significant (i.e. $\mathbf{P}>0.05$ ).

${ }^{1}$ A significant difference is no longer present if the frequency is calculated for a single (first) observation done on each patient. 
group than in the gastric ulcer and control groups $(P=0.5)$, and the amounts were similar in controls and the gastric ulcer group. This cannot be interpreted as meaning that less protein is present in the gastric juice of patients with gastric carcinoma as in many the amount initially applied could not be determined on the scale of the scanning apparatus and the electrophoresis was repeated with smaller amounts applied.

In this study too, bile and bromsulphthaleinstained specimens were discarded and it was possible that those containing bromsulphthalein may have had a higher protein content than those free of it, the bromsulphthalein entering the stomach bound to albumin and not with duodenal reflux as it was considered to do. In a group of 14 patients, some specimens free of bile and bromsulphthalein and others containing bile and bromsulphthalein were electrophoresed; the most frequent effect of duodenal reflux was found in band 5, where nine showed a reduction in this band, three showed an increase, and two showed no change. The group of five observations discarded because of bromsulphthalein or bile staining were entirely from the gastric ulcer group. Consequently, we do not feel that the method of selection could account for the results outlined above; if any effect is produced by this selection, it would tend to minimize the changes in band 5 found in the gastric ulcer group.

It is realized that the amount of protein staining material in each band is only relative. Consequently, if the albumin band is increased, there must be a reduction of the other bands. The above results are also consistent with the fact that the albumin band may be unchanged and a reduction of the other bands be present in the above two conditions. However, from evidence discussed later, this latter interpretation is considered unlikely.

\section{DISCUSSION}

Protein loss into the gastrointestinal tract was first adequately demonstrated by Citrin, Sterling, and Halsted (1957). They demonstrated increased loss of radioiodinated serum albumin into the stomach of a patient with hypertrophic gastritis. Subsequently Gordon (1959) introduced labelled polyvinylpyrrolidine to estimate albumin loss into the gastrointestinal tract. Using this technique a series of diseases has been identified with increased protein loss into the gut (Gordon, 1959; Schwartz and Jarnum, 1959; Jarnum and Schwartz, 1960). Among the diseases characterized by increased protein loss into the gut is gastric carcinoma (Jarnum and Schwartz, 1960). Hence, the increased loss of albumin into the gastric juice in patients with gastric carcinoma demonstrated in the present study is consistent with findings of increased albumin loss into the gut demonstrated by other techniques.

The study of the protein fractions in gastric juice and other intestinal secretions is complicated by the fact that the pattern is markedly altered by autodigestion unless care is taken to prevent it (Piper et al., 1962). Peptic digestion can be inhibited relatively easily by maintaining the $p \mathrm{H}$ above 7 . At this $p \mathrm{H}$ level, however, tryptic digestion would occur if reflux of duodenal contents took place. The former has been prevented in the present study by maintaining the $p \mathrm{H}$ above 7 , and the latter by discarding any specimen that contained any evidence of regurgitated bile or bromsulphthalein. In the studies of Glass and Ishimori (1961) and of Henning, Kinzlmeier, and Demling (1953) no precautions were taken to prevent peptic digestion and we consider that their findings are of doubtful value because of this omission. This is of particular importance when studies are made of the albumin band in gastric juice because of the effect upon it of peptic digestion (Piper et al., 1962). In neutralized gastric juice tryptic digestion could be a major source of error because the gastric juice is kept and dialysed at a $p \mathrm{H}$ where tryptic digestion would be possible. We have noted too that many specimens that contained no obvious bile gave a blue colour of bromsulphthalein, and often when no bromsulphthalein was visible in the diluted gastric juice collected, the lyophilized material showed a slight blue coloration when mixed with buffer, indicating some duodenal reflux.

Glass and Ishimori (1961) found massive leakage of albumin in the gastric juice of carcinoma patients with anacidity and they suggested that this peak may be of diagnostic value in patients with gastric carcinoma. The present study has confirmed the large albumin component in the gastric juice of patients with gastric carcinoma, but a similar finding was present in patients with simple gastric ulcer, and the overlap of the albumin component in gastric cancer patients with the latter group, and the lack of a clear demarcation between the controls and the cancer group deprives this value of any diagnostic significance (Fig. 5). It is felt that the findings of a large albumin peak by Glass et al. (1957) was partly an indirect reflection of the frequent anacidity of patients with advanced carcinoma of the stomach, the anacidity preventing the peptic digestion of the albumin band in the cancer group that occurred in varying degree in the gastric ulcer group.

The nature and cause of the protein loss into the stomach of gastric ulcer and cancer patients is not clear. The peaks of the gastric juice electrophorogram do not coincide in migration distance or 
proportion with the components in the serum, so it probably does not merely reflect loss of serum from the surface of the ulcer or carcinoma. The loss of albumin in cases of gastric ulcer is consistent with other biochemical and clinical studies which have demonstrated that the serum proteins in peptic ulcer patients tend to be reduced (Riggs, Reinhold, Boles, and Shore, 1941; Polozhentsev, 1960); also the findings of a hypoproteinaemic syndrome in some patients with a large gastric ulcer is a well known clinical observation (Jones and Gummer, 1960). Gastric carcinoma also has been demonstrated to be a common cause of the protein-losing gastroenteropathy syndrome (Jarnum and Schwartz, 1960). We found no correlation between the size of the ulcer and the albumin loss, and though in some cases the albumin band became smaller as the ulcer healed, this was not a constant finding. There was also no relationship between the site of the ulcer and the albumin loss. Another possibility is that it is a reflection of the gastritis surrounding the ulcer, but if this were so, one would expect the albumin band to decrease as the ulcer healed. It is likely that gastric mucus may contribute much of the albumin component of gastric juice; Horowitz and Hollander (1961) showed that on electrophoresis anacid gastric mucinous secretions showed a large anodal band that had the electrophoretic and immunological properties of albumin.

The occurrence of a different pattern because of the increased frequency of band 2 in the electropherogram of gastric juice in $56 \%$ of patients with gastric ulcer (on the first study) is of interest because a qualitative difference in the gastric juice of ulcer and non-ulcer patients has not previously been demonstrated. The possible interpretation of this band has been discussed previously (Piper et al., 1962). The significance of this band depends upon its identification and the investigation of its effect on gastric secretion and ulcer formation. The latter studies are in progress.

In the elucidation of the significance of the various bands in the electropherogram of gastric juice it must be determined that some of the lesser peaks are not the result of partial autodigestion. Though, with the technique outlined, peptic digestion can be prevented within the gastric lumen, the neutralizing solution probably does not enter the gastric glands, and it is unknown to what extent digestion can occur during the short time the secretions are within the gland lumen. If one compares the bands observed with those found when albumin or gastric juice is digested by pepsin in vitro (Piper et al.,
$1962)$ it is found that this interpretation is unlikely; with the digestion of albumin there were no proteinstaining materials that moved more rapidly towards the anode than albumin, nor were there any cathodal bands. Glass et al. (1957) considered that the bands that moved slowly towards the anode consisted chiefly of mucoproteins; preliminary observations agree with this, most of the P.A.S.-staining material being situated in the region of bands 2,3 , and 4 . It is realized too that the results stated are not quantitative and at the most semi-quantitative. Quantitative determination depends upon knowledge of the rate of secretion which requires continuous aspiration, which is not possible if intragastric neutralization is to be performed.

We wish to thank Professor Blackburn, Dr. Stanley, and Dr. Morell, for helpful advice given throughout the project.

\section{REFERENCES}

Citrin, Y., Sterling, K., and Halsted, J. A. (1957). The mechanism of hypoproteinemia associated with giant hypertrophy of the gastric mucosa. New Engl. J. Med., 257, 906-912.

Glass, G. B. J., and Ishimori, A. (1961). Passage of serum albumin into the stomach. Its detection by paper electrophoresis of gastric juice in protein-losing gastropathies and gastric cancer Amer. J. dig. Dis., N.S., 6, 103-133.

_- Stephanson, L., and Rich, M. (1957). Paper-electrophoretic analysis of gastric juice in health and disease, and its physiological and clinical significance. Gastroenterologia (Basel), 86, 384-395.

Gordon, R. S. Jr. (1959). Exudative enteropathy. Lancet, 1, 325-326.

Heiskell, C. L., Wada, T., Stempien, S. J., Fukuda, M., Nakagawa, S., Yachi, A., Dagradi, A., and Carpenter, C. M. (1961). Normal serum proteins in gastric juice. Gastroenterology, 40, 775-781.

Henning, N., Kinzlmeier, H., and Demling, L. (1953). Uber die elektrophoretisch darstellbaren proteine normaler und pathologischer Magensäfte, Münch. med. Wschr., 95, 423-426.

Holman, H., Nickel, W. F. Jr., and Sleisenger, M. H. (1959). Hypoproteinemia antedating intestinal lesions, and possibly due to excessive serum protein loss into the intestine. Amer. J. Med., 27, 963-975.

Horowitz, M. I., and Hollander, F. (1961). Serum proteins in anacid gastric mucinous secretions. J. biol. Chem., 236, 770-773.

Jarnum, S., and Schwartz, M. (1960). Hypoalbuminemia in gastric carcinoma. Gastroenterology, 38, 769-776

Jones, F A., and Gummer, J. W. P. (1960). Clinical Gastroenterology. Blackwell, Oxford.

Kay, A. W. (1953). Effect of large doses of histamine on gastric secretion of $\mathbf{H C l}$. Brit. med. J., 2, 77-80.

Kohn, J. (1957). A cellulose acetate supporting medium for zone electrophoresis. Clin. chim. Acta, 2, 297-303.

Piper, D. W., Stiel, M. C., and Builder, J. E. (1962). Electrophoretic analysis of human gastric juice. Gut, 3, 349-360.

Polozhentsev, S. D. (1960). A study of the blood proteins by the method of electrophoresis in relation to resection of the stomach and blood transfusion. Vestn. Khir. 84, (5), 60-63.

Riggs, H. E., Reinhold J. G., Boles, R. S., and Shore, P. S. (1941). Qualitative circulatory deficiencies observed in peptic ulcer. Amer. J. dig. Dis., 8, 383-387.

Schwartz, M., and Jarnum, S. (1959). Gastrointestinal protein loss in idiopathic (hypercatabolic) hypoproteinaemia. Lancet, 1 , 327-330. 